\title{
Del lectocentrismo al plurinormativismo. Reflexiones sobre la variedad del español como lengua segunda o extranjera
}

\author{
From Lectocentrism to Plurinormativism. \\ Reflections on the Variety of Spanish in \\ Teaching as a Second or Foreign Language
}

\section{MARÍA ANTONIETA ANDIÓN HERRERO}

\author{
Universidad Nacional de Educación a Distancia, Facultad de Filología. España.
}

Correo electrónico: maandion@flog.uned.es

\begin{abstract}
Hoy la enseñanza del español como lengua segunda o extranjera (E-L2/LE) se encuentra abocada a la reflexión sobre el modelo lingüístico de enseñanza-aprendizaje y a cómo abordar, en ese marco, la variedad y variación de nuestra lengua. Las incógnitas sobre su idoneidad y adscripción a un país o comunidad de habla concreta, la relación entre corrección y prestigio, entre otras, son frecuentes en autoridades académicas, creadores de manuales, diseñadores curriculares y docentes. Desde la perspectiva de E-L2/LE, reflexionamos en este artículo sobre conceptos y actitudes asociadas a las cuestiones anteriores: etnocentrismo (con su derivado lectocentrismo) y plurinormativismo, y sus relaciones con la variedad y variación del español. Analizamos sus vínculos con el estándar, la variedad y la norma, las evidencias lingüísticas y extralingüísticas que condicionan el hispanismo y el impacto que ha tenido esta postura institucional académica en la enseñanza del E-L2/LE y sus manuales didácticos.
\end{abstract} ñol-L2/LE.

Palabras claves: etnocentrismo, lectocentrismo, plurinormativismo, panhispanismo, espa-

Currently, an important issue to discuss in the teaching of Spanish as a second or foreign language (S-SL/FL) is the linguistic model of teaching-learning and on how to approach, in this context, the variety and variation of our language. Doubts about the suitability of the linguistic model, its ascription to a particular Spanish-speaking country or community, or the relation between correction and prestige are usual in academic authorities, manual creators, curriculum designers and teachers. From the perspective of S-SL/FL, in this article we reflect on concepts and attitudes associated with those issues: ethnocentrism (with its derivative lectocentrism) and plurinormativism, discussing their connections with the variety and variation of Spanish. We also analyze their association with the standard, the variety and the norm, the linguistic and extralinguistic evidences conditioning the 
Hispanism, and the impact of this academic institutional position on the teaching of S-SL/FL and the teaching manuals.

Key words: ethnocentrism, lectocentrism, plurinormativism, panhispanism, Spanish-FL/SL.

\section{INTRODUCCIÓN}

La extensión geográfica y demográfica del español apoya su candidatura internacional y destaca el valor de la industria del español como lengua segunda/extranjera (E-L2/LE). ${ }^{1}$ Sus 26 millones de estudiantes ${ }^{2}$ afianzan nuestra lengua como recurso económico y fuente laboral para los países hispánicos. Tanto fuera como dentro de estos, parece imposible su enseñanza sin tomar en consideración la variedad de la lengua. Sin embargo, qué español enseñar o cómo abordar la variación desde una norma concreta o estandarizada sigue siendo una preocupación para autoridades académicas, manualistas, diseñadores curriculares y profesores.

Desde hace años, la comunidad científica relacionada con el español y su enseñanza a no nativos reflexiona sobre la adecuación de la variedad de la lengua a diferentes contextos de enseñanza-aprendizaje, el modelo lingüístico y sus rasgos preferentes y periféricos, las actitudes de docentes y discentes hacia la variedad... en eventos científicos, congresos, seminarios y jornadas de E-L2/LE. En estas últimas décadas, la Asociación para la Enseñanza del Español como Lengua Extranjera (ASELE) ha demostrado su interés especialmente por este tema: dedicó su undécimo Congreso del 2000 a “¿Qué español enseñar? Norma y variación lingüística en la enseńanza del español como lengua extranjera”, repitió en el décimo tercero de 2002, "El Español, Lengua del Mestizaje y la Interculturalidad", y en 2016 se centró en "Panhispanismo y variedades en la enseñanza del español-L2/LE”. Por su parte, el Sistema Internacional de Certificación de Español como Lengua Extranjera (SICELE) celebró en noviembre de 2016 su tercer Congreso en Alcalá de Henares, España, y una de las líneas propuestas fue "Evaluación y variedades lingüísticas del español". La Asociación Alemana de Hispanistas, en su vigésimo primer Congreso (primavera de 2017, en Múnich), reunió a interesados alrededor de los "Lugares del hispanismo en un mundo globalizado”. También la Asociación de Lingüística y Filología de América Latina (ALFAL) en su décimo octavo Congreso, celebrado el verano de ese mismo año en Colombia, dedicó una de sus secciones a la Glotopolítica, en la que se presentaron varias ponencias sobre la variedad del español y su enseñanza como lengua extranjera.

\footnotetext{
${ }^{1}$ Aunque reconocemos la distinción desde el punto de vista sociolingüístico entre segunda lengua y lengua extranjera (la segunda lengua es la que se enseña en un entorno donde es medio de comunicación y la extranjera, donde no lo es [Richards, Platt y Platt 1997]), no la asumiremos aquí por no ser relevante para este artículo.

${ }^{2}$ Esta cifra resulta de sumar un $25 \%$ de la oferta docente privada a los 21 millones de alumnos de español que estudian en 106 países no hispánicos (Instituto Cervantes 2016).
} 
Motivado por este interés, el presente artículo tratará sobre la variación/variedad del español como L2/LE: el estado de la cuestión y los aspectos teóricos, circunstanciales y de actitudes que condicionan diferentes planteamientos alrededor de este tema. Aportamos reflexiones críticas sobre modos de proceder heredados, actuales y futuros, en cuyo marco glotopolítico presentamos un término novedoso (lectocentrismo), relacionado con el centrismo lingüístico, especialmente entre geolectos o variedades de una lengua. ${ }^{3}$ Además, ofrecemos recomendaciones sobre modos de actuación aplicados a su enseñanza-aprendizaje.

\section{MARCo TEÓRICO Y CONCEPTOS BÁSICOS}

Es evidente que el español es una lengua variable, tanto como para considerarla, como lo hace García de Diego (1950, p. 107), un "complejo dialectal", en el que conviven un alto nivel de estandarización, en el sentido de lo común y lo compartido, y grados diferentes de fragmentación. Demonte (2003) define claramente esta relación dialéctica: "todos hablamos alguna variedad de una lengua abstracta común y compartimos propiedades de varios dialectos. Somos únicos y mestizos; nacionales, internacionales y locales" (p. 1). Sin embargo, en dicha cohabitación existen grados diferentes de tolerancia (inter)dialectal y proliferan creencias y actitudes de naturaleza glotopolítica. Conceptos como estándar, geolecto y norma participan en esta compleja relación que implica tanto al hablante individual (su idiolecto) como a su comunidad idiomática (en nuestro caso, la de la lengua española).

El concepto de estándar podemos abordarlo desde un punto de vista lingüístico, más riguroso, o desde el popular, menos especializado. Dentro del primero, cuando estándar se asimila a 'lengua general', se refiere a los rasgos lingüísticos compartidos por el colectivo de sus hablantes (Andión 2007). No se identifica el estándar con variedades concretas porque se neutralizan las marcas geográficas (diatópicas) y sociales (diastráticas) (Moreno 2010), y se rechaza lo exclusivo a una o pocas variedades aunque pueda ser prestigioso. Este concepto crea necesariamente casillas vacías en el modelo lingüístico para los casos en los que no existen formas comunes para todas las variedades, ${ }^{4}$ como en las letras $z / c(+e / i)$, realizadas mayoritariamente por los hispanohablantes como fricativas alveolares y muy minoritariamente como fricativas interdentales.

Generalmente relacionamos el estándar con un modelo escrito, correcto y prestigioso, propio de hablantes cultos (Moreno 2010). Pero si nos detenemos en esta caracterización, enseguida aparecen excepciones: el estándar también se manifiesta en la oralidad y es posible

\footnotetext{
${ }^{3}$ No distinguiremos entre dialecto, geolecto y variedad; todos son "variantes geográficas de una lengua" (Alvar 1996). Remitimos al autor como autoridad en este tema. Evitaremos dialecto por sus connotaciones peyorativas ("inferior", "popular", "poco prestigioso" y, en algunos casos, "rural") (Andión y Casado 2014). Tampoco asociaremos geolecto o variedad a una "modalidad relegada, desviada o desprestigiada" (Moreno 2014).

${ }^{4}$ Sin poder profundizar en ella, reconocemos la falta de sensibilidad de esta implicación conceptual reductora del estándar con la diversidad y el pluricentrismo, en el sentido que lo trata Arnoux (2015).
} 
calificar de "estandarizado" el discurso oral sin marcas geolectales reconocibles, frecuente en situaciones muy formales y contextos internacionales (Andión 2007). Asimismo, las etiquetas de "correcto" y "culto" varían según a qué variedad se apliquen y de quiénes sean sus referentes. A esta diversidad de criterios normativos no son ajenos ni siquiera los profesores de español en formación. Por ejemplo, en el marco de nuestra docencia en el máster y del experto en E-L2/LE (de la Universidad Nacional de Educación a Distancia, Espańa, cursos de 2014 a 2016), cuando les pedimos a nuestros alumnos (124 profesores) que se identificaran dialectalmente, no todos manifestaron la misma idea sobre el prestigio de sus rasgos lingüísticos más característicos: cinco de ellos mencionaron la geminación de la -s (ju[tt]o justo) como propia de su geolecto (dos andaluces, un castellano-manchego, un rioplatense y un chileno) y todos la consideraron un rasgo culto, excepto los andaluces.

Si el estándar se identifica con un geolecto al que se otorga autoridad e importancia -en definitiva, prestigio-, consecuentemente, las restantes variedades pasan a ser peor valoradas y, por ende, son víctimas de lo que más adelante definiremos como lectocentrismo. La norma, o "conjunto de usos lingüísticos consensuados por [su] comunidad de hablantes como correctos y aceptables" (Andión, 2008, p. 18), de la variedad privilegiada se convierte en ejemplar para toda la comunidad lingüística; también, en espacios más reducidos, para otras variedades regionales dentro de un mismo país. ${ }^{5}$

El estándar y la norma forman una red conceptual alrededor del geolecto: el estándar (como 'lengua general') está por encima de la norma o identifica una representación de la lengua (como 'variedad o geolecto prestigioso'), y la norma forma parte del geolecto pues atiende a los criterios de corrección de un grupo selecto de sus hablantes. Por su parte, los geolectos establecen una relación de inclusión - para algunos, de subordinación- respecto de la lengua, tanto de la lengua entendida como sistema abstracto (la langue de Saussure), como del idioma, una entidad concreta, que identifica a una comunidad cultural o histórica en su totalidad (De Andrés, 1997; Coseriu, 1981). A su vez, los geolectos se diferencian entre sí y distinguen, como modalidades lingüísticas, a sus hablantes enmarcando el territorio donde se usan.

También, en relación con el prestigio, la capital de un país tiene protagonismo normativo por radicar en ella el poder político, la administración del Estado, las instituciones de enseñanza e investigación, las empresas de comunicación con sus editoriales, periódicos, revistas, cadenas de televisión, etc. En el mundo hispánico, existen geolectos a los que los hablantes, tanto nativos como no nativos, les otorgan mayor consideración; lo cierto es que "todas las zonas del mundo hispánico ostentan más de un modelo que goza de reconocimiento y prestigio lingüístico” (Andión y Casado 2014).

\footnotetext{
${ }^{5}$ Esta situación de ámbito más restringido, el de los subgeolectos (variedades regionales), puede ejemplificarse en la diferencia de prestigio entre las hablas del interior y la costa o entre zonas de un país. Por motivos de espacio, no podemos adentrarnos en esta interesante deriva del tema.
} 


\section{ETNOCENTRISMO Y LECTOCENTRISMO}

En el caso del español, la compleja relación entre su(s) norma(s) y el estándar obliga a tratar aspectos de índole social, cultural e histórica. Empecemos por el etnocentrismo o (socio)centrismo cultural (Chiriguini y Mancusi 2008). Este concepto antropológico tiene tres posibles interpretaciones: 1) la moderada o tenue califica el etnocentrismo de "natural y consustancial", un modo de reforzamiento o impermeabilidad de las culturas para preservar los valores propios (Lévi-Strauss 1974); la neutra lo considera una "actitud a partir de la cual las costumbres e ideas de otras sociedades pueden ser evaluadas desde el contexto de la cultura de uno mismo" (Ember y Ember 1974, p. 461); y 3) la severa lo interpreta como una idea de superioridad cultural de un grupo respecto de otros, cuyos comportamientos juzga desde sus normas (Sumner 1959 [1906]). La primera interpretación respondió en su momento a la "amenaza" que suponía la globalización para las identidades culturales, entendidas como un conjunto de herencias, creencias y valores grupales, entre los que se encuentra la lengua (y a nivel más concreto, el geolecto); ${ }^{6}$ la segunda, aunque sin ser errónea, oculta que una posición etnocéntrica implica la inferioridad de las otras culturas pudiendo llegar al racismo y la xenofobia, consecuencias que evidencia la tercera interpretación. Las manifestaciones del etnocentrismo pueden ir desde el desprecio hegemónico hasta el paternalismo, que puede contar con la complicidad condescendiente - a veces inconsciente- de quienes son sus víctimas.

El etnocentrismo es una actitud psicológica de repudio ante lo inesperado, desconocido o diferente, ajeno a lo identitario (Aguilera 2008). Quienes, desde su identidad cultural, practican el etnocentrismo juzgan de forma negativa - para algunos, pedante y soberbia- las costumbres, los comportamientos, la cultura... y como parte de ella, la lengua, de otros. Hay palabras que captan especialmente esta visión: exótico, salvaje (heredero del bárbaro griego), extraño, primitivo, chocante, extravagante...

El encuentro entre sociedades con desigual desarrollo socioeconómico e histórico suele propiciar el etnocentrismo, postura histórica vinculada a la expansión del mundo occidental y común en los grupos humanos. El evolucionismo cultural de este proceso es calificado de "canibalismo intelectual" cuando "no reconoce la enorme riqueza de la pluralidad y la diversidad cultural" (Lévi-Strauss, apud Aguilera 2008: 13).

En un plano lingüístico, el glotocentrismo alude al desequilibrio de prestigio entre lenguas dominadoras y dominadas (Walsh 2005), que desfavorece a estas últimas sobre todo en convivencias diglósicas. Glotocentrismo es una palabra recurrente al tratar, por ejemplo, la relación entre las lenguas indoamericanas y el español durante la colonización (y posteriormente). Consideramos que su equivalente en un plano interdialectal merece un término propio, inexistente hasta ahora y al que aquí proponemos llamar lectocentrismo

\footnotetext{
${ }^{6}$ Téngase en cuenta que, aunque la identidad cultural es un concepto complejo, la identificación lingüística tiene un papel importante dentro de ella como determinante de la etnicidad: "ethnicity can be thought of as a sense of group identify from real of perceived conmmon bonds such as language, race or religión" (Edwards 1994: 125).
} 
(del griego $\lambda \dot{\gamma} \gamma \varepsilon l v$ 'hablar'), que identificaría la creencia de superioridad de un geolecto o variedad, considerado ejemplar y modélico, sobre los restantes de su lengua. En esta situación, la variedad favorecida es calificada de "pura" o "correcta", mientras que las otras se consideran alteraciones o desviaciones.

En el mundo hispánico y desde épocas tempranas, el lectocentrismo es evidente entre el romance castellano y otras lenguas y dialectos ibéricos, a los que impuso su hegemonía. Ya en la España del siglo XV, el panorama lingüístico mostraba consecuencias lectocentristas: en la parte central, el leonés pervivía solamente en el habla rústica; es el sayagués de los pastores de Juan de la Enzina y Lucas Fernández. En el norte de Asturias —región más dialectal dentro del leonés-, se usaban mayoritariamente castellanismos en las notarías y algunos asturianismos. En Valencia existía un grupo importante de poetas bilingües (Narcís Viñoles, Comendador Escrivá, Alonso de Córdoba, Francesc Carrós, Mossèn Gazull, Juan Fernández de Heredia). Los poetas gallegos mezclaban su lengua con el castellano (Macías) o usaban únicamente este (Juan Rodríguez de Padrón). El aragonés, muy influido también por el dialecto de Castilla, desapareció pronto del uso literario y notarial: su actividad literaria había disminuido por la presión del castellano y del catalán. En este último, hay casos como el de Pedro Moner que escribe la mayoría de sus obras en castellano. En los sucesivos siglos, el castellano siguió cumpliendo todos los requisitos que lo afianzaban como lengua, a saber, historicidad, vitalidad, autonomía y estandarización (Stewart 1974 [1962]).

Este castellano peninsular -ya extendido, pero no homogéneo- contenía tres variedades: la norteńa, la toledana y la andaluza (marcadamente innovadora) (Moreno, 2006). La primera satisfizo las exigencias de pureza y corrección de la Real Academia Española (RAE), que en ella encontraría el paradigma de la lengua nacional, el que "fija(ba), brilla(ba) y da(ba) esplendor”. Durante siglos esta creencia motivó que la variedad castellana fuera el referente a partir del cual se explicaba la variación del español y que, por ejemplo, el seseo haya sido tratado como un fenómeno divergente del patrón distinguidor $/ \mathrm{s} /-/ \theta /$, a pesar de que la mayoría hispanohablante era y es seseante.

Hoy las posturas son otras. En una entrevista al diario español El País, José Manuel Blecua, entonces director de la RAE, afirmaba al respecto del seseo y su inclusión en el tomo dedicado a la fonética y la fonología de la Nueva gramática: "solo somos un $10 \%$ los hablantes que no lo hacemos [sesear]. Lo curioso es que en España haya todavía gente que cree que el seseo es una incorrección" (Rodríguez 2011). Realmente son esperables estas creencias tras siglos de lectocentrismo. De hecho, desde la variedad castellana, el seseo se asocia a síntomas "de incultura, de falta de educación" y de incorrección (González Cruz 1995, p. 719).

Innegablemente la variedad castellana ha disfrutado de un especial halo de prestigio y representatividad del español (Moreno 2006) típicamente lectocentrista. ${ }^{7}$ Puede

\footnotetext{
${ }^{7}$ No olvidemos que la primera vez que se trató el castellano como un dialecto más fue en el siglo XX, en el Manual de dialectología hispánica. El español de España, cuyo director fue Manuel Alvar López.
} 
que influya su mayor visibilidad y referencia internacional; por ejemplo, destaca Europa, y por ende, España, en la relevancia del español como mercado e industria dentro de la comunidad hispanohablante. ${ }^{8}$

En América, el etnocentrismo está relacionado con la experiencia colonial y el encuentro con los pueblos amerindios (Lander 2005), que no estuvieron exentos de mestizaje. Desde el siglo XIX, algunas voces se han desmarcado de las consecuencias lectocentristas de esta tendencia. En su Gramática de la lengua castellana destinada al uso de los americanos, Bello (1853 [1847]) declaraba: "No tengo la pretensión de escribir para los castellanos. Mis lecciones se dirigen a mis hermanos, los habitantes de Hispano-América" (p. 9). Más recientemente, aparecen otras voces: "En el caso del espańol, que es la lengua nacional de una veintena de países, proponer como estándar general la modalidad de prestigio propia de una región particular, implica una valoración inaceptable que conduce a una selección imposible de realizar sobre una base válida desde el punto de vista lingüístico" (Alba 2004: 328).

La conquista propició "por muchos años, que la norma española peninsular resultara favorecida frente a normas criollas que iniciaban su andar a finales de la colonia en varios puntos del Nuevo Continente" (Vergara 2007: 17). Y ello ocurrió pese a que los rasgos del español que prendieron en América eran marcadamente meridionales (seseo, yeísmo, formas complementarias etimológicas). No obstante, las normas de las nuevas repúblicas mantuvieron una unidad niveladora a cierta distancia del modelo espańol.

También entre los hispanoamericanos existen creencias lectocentristas. Se piensa que los colombianos, especialmente de Bogotá, hablan el mejor español de esa parte del mundo (Lozano 1999, Moreno 2010, Patińo 2004): "El habla culta de Bogotá y de otras ciudades del interior goza de la reputación popular de ser el español 'más puro' de Hispanoamérica, prestigio alimentado por la existencia del Instituto Caro y Cuervo" (Lipski 1996: 227). Sostienen esta creencia la autoridad indiscutible de la institución lingüística y el interés y gusto del pueblo colombiano por su lengua. No olvidemos que la Academia Colombiana de la Lengua fue la primera fundada en América (1871). Es posible que esta habla conservadora, como la castellana, haya sido "contagiada" por su halo de prestigio."

Desde mediados del siglo pasado, es interesante observar un paulatino proceso deslocalizador del modelo del español. La variedad castellana, presionada por el panhispanismo y el plurinormativismo $(\$ 4)$, se ha empezado a sentir poco representativa de la mayoría hispanohablante, que no distingue $/ \mathrm{s} /-/ \theta /$, no utiliza vosotros o a por, ni es laísta.

En el ámbito de la enseñanza de lenguas extranjeras o segundas lenguas, el etnocentrismo ha estado vinculado, en principio, a la relación entre culturas y no entre

\footnotetext{
8 "Dos tercios del PIB vinculado al español se generan en dos grandes áreas. Por un lado, Norteamérica (México, Estados Unidos y Canadá) y por otro la Unión Europea. Entre estas dos regiones suman el $78 \%$ del poder de compra de los hablantes de español en el mundo" (Instituto Cervantes 2016: 19-20).

${ }^{9}$ Recordemos que Bogotá pasó a virreinato a principios del siglo XVIII, por lo que recibió a representantes de la política y administración coloniales; y a través de ellos, las costumbres y norma castellanas, que se convirtieron en únicas referencias por su aislamiento geográfico y escasa relación comercial con el Caribe.
} 
comunidades de habla de una misma lengua. ${ }^{10}$ Se ha relacionado esta postura antropológica con la interpretación intolerante de los valores culturales idiosincrásicos de la lengua meta desde la perspectiva de la lengua materna del aprendiz. Hablamos de estereotipos y prejuicios, que pueden ser contrarrestados desde un enfoque intercultural (Baralo 2002). En sentido general, el etnocentrismo es uno de los principales desestimuladores del aprendizaje: es difícil aprender lo que no se aprecia.

Más concretamente, el espańol-L2/LE se convierte en escenario del lectocentrismo cuando una de sus variedades es considerada, en exclusiva, "el" modelo de enseñanza/ aprendizaje y es tratada como equivalente absoluto de la lengua sin reconocer sus limitaciones geolectales. El argumento más citado para favorecerla suele ser el prestigio, razón social subjetiva y heredada. Según evidencia Andión (2013) en su estudio sobre identidad dialectal, actitudes y prácticas docentes en profesores brasileños de E-L2/LE, es común que los hablantes de la variedad etiquetada como "prestigiosa" sean los mismos que la califican -y no pocas veces la imponen- como modelo o estándar.

\section{Del panhispanismo al plurinormativismo}

En oposición a las tendencias anteriores se posicionan el panhispanismo y el plurinormativismo. En el terreno cultural, económico y político, la corriente panhispánica surge en América a principios del siglo XX para "potenciar la pertenencia a un tronco común, el de la latinidad e hispanidad, para enfrentar las apetencias del capitalismo inglés o norteamericano, de modo que las afinidades con España en cuanto a 'raza, lengua y religión' confirmaran una fuerte cultura que se opusiera a lo anglosajón” (González Aróstegui 2003: 1-2). En ese momento se oponía al panamericanismo, que rechazaba la influencia española tras la descolonización en ámbitos ajenos a la política y propugnaba los vínculos con el nuevo imperio, los Estados Unidos de América.

El término panhispanismo se aplica a un terreno exclusivamente lingüístico en la segunda mitad del siglo XX en relación con dos tendencias: por una parte, las áreas particulares de realización del español, principalmente urbanas; y, por otra, lo que ellas comparten y que, activa o pasivamente, les es común. Esta última asociación semántica se quedó con la denominación (Moreno, 2006, pp. 76-77). Favorecen el panhispanismo que la lengua sea sentida como una, aunque variada; que no existan rechazos serios de los hablantes hacia otras variedades; y que el mundo hispánico tienda a homogeneizarse influido por los medios de comunicación (Moreno 2006: 86-87).

\footnotetext{
${ }^{10}$ Entendemos por comunidad de habla al grupo de hablantes que, además de compartir una o más lenguas (o geolectos), comparten normas y valores de naturaleza sociolingüística: las mismas actitudes lingüísticas, reglas de uso y criterios sobre la valoración social de hechos lingüísticos, como, por ejemplo, la norma culta, lo correcto o incorrecto, lo vulgar, lo familiar, etc. Sus vínculos crean una identificación social y una solidaridad grupal muy fuertes, que los hacen cumplir normas sociolingüísticas para mantener la marca e identidad del grupo (Andión y Casado, 2014).
} 
La visión globalizadora del panhispanismo consensua posiciones sobre lo aceptable y correcto para cada variedad, y coordina las posturas que establecen estas normas y que describen un modelo esencial pero no único. Así, la ortografía, la gramática y el léxico - en un sentido decreciente de unidad- reúnen componentes comunes a las variedades del español que definen el estándar de la lengua. Como es delicado mantenerse en un punto de consenso y equilibrio entre la unidad y la diversidad, no debe mostrarse un especial apego a una de las normas de la lengua, como fue usual hacia la castellana peninsular por parte de la política lingüística de la RAE en siglos pasados. Hacerlo así traicionaría el principio del panhispanismo adoptando una postura lectocentrista y convirtiendo el modelo en exonormativo para las demás variedades.

El panhispanismo, como "sistema de ideas, o mejor, de ideologemas, ${ }^{11}$ en torno al español históricamente localizado que concibe el idioma como la materialización de un orden colectivo en el cual España desempeña un papel central" (Valle 2007: 46), debe rechazar el protagonismo geopolítico europeo. Para ello son necesarias iniciativas -y apoyo económico- plurales de todos los países hispánicos pues la focalización de España podría ser tachada de imperialismo lingüístico, postura inaceptable (Moreno 2006).

El panhispanismo se orienta a una concepción de la lengua donde unidad y diversidad mantienen un equilibrio dinámico y flexible -entiéndase no perfecto ni inmóvil-, coherente con su evolución histórica y permeable al cambio, que señala a una identidad común hispánica con subidentidades particulares. Voces tan autorizadas como la de Bello (1853 [1847]) clamaban desde hace más de un siglo que "Chile y Venezuela tienen tanto derecho como Aragón o Andalucía para que se toleren sus accidentales divergencias, cuando las patrocina la costumbre uniforme y auténtica de la gente educada" (vii).

El reconocimiento del plurinormativismo se pronuncia en sentido contrario al lectocentrismo. Se enmarca en el relativismo cultural, que practica el respeto a otras culturas (lenguas) sin dejar de valorar la propia. Ello conduce a la aceptación de la pluralidad cultural y, también, lingüística. En este terreno, el reconocimiento de que las lenguas son plurinormativas aparece ya desde los años 60 del pasado siglo. El español lo es incuestionablemente:

Lo que se aprecia en la Hispania de hoy es una gran variedad de maneras de hablar en lo que estimamos es una misma lengua. Este 'sentimiento de unidad' obedece al hecho de que se trata, prácticamente, de un único sistema (o diasistema) lingüístico con una multiplicidad de normas (en sentido sociolingüístico), por aquello de que toda lengua es plurinormativa, sin dejar de ser ella misma. Así se da la diversidad dentro de la unidad (Rabanales 1998: 133).

\footnotetext{
${ }^{11}$ Entendamos ideologema como signo ideológico que muestra la adscripción cultural y social de un sujeto, su sistema de valores (Cros 2009).
} 
El carácter plurinormativo del español se sostiene por la aceptación consciente de los hispanohablantes de que existen usos modélicos y ejemplares que pertenecen al mundo hispánico y a cualquiera de sus variedades. Una suerte de democracia lingüística ha favorecido nuestra lengua con "una norma genérica, pluricéntrica, que vincula elementos de distinta procedencia y origen y hace que los hablantes de espańol podamos entendernos" (Bravo 2008: 17). Están dadas las condiciones para que no se estigmaticen características diferenciadoras de las normas cultas de las variedades (Morgenthaler 2008), por lo que no se justifican actitudes lectocentristas.

En este sentido, el español encontró en sus Academias americanas un primer paso de reconocimiento, diálogo, debate y colaboración, compartido con la RAE, que hoy vive un momento de esplendor. La Ortografía de la Lengua Española (1999) mostró que se había tomado el camino del acuerdo entre las Academias, dispuestas a debatir y consensuar su normalización en un concierto donde se sacrifican particularidades en pro de la descripción del modelo de la mancomunidad lingüística hispánica. Consecuencia de esta política fue la publicación del Diccionario de la lengua española (2001), con 28000 variantes americanas en artículos, acepciones, marcas... Acción colegiada que, según se afirma en el prólogo, situaba a la obra "en el camino correcto para conseguir un diccionario verdaderamente panhispánico, reflejo no solo del español peninsular sino del de todo el mundo hispanohablante" y permitía a la RAE "servir de modo eficaz, con el concurso de sus Academias hermanas, a la unidad del español”. En 2004 el nuevo Diccionario de la lengua española se reconocía como resultado del trabajo colaborador de la Asociación de Academias de la Lengua Española (ASALE). Otras obras académicas de marca panhispánica son el Diccionario panhispánico de dudas (2005) y la Nueva gramática de la lengua española (20092011) con una voluminosa presencia de rasgos geolectales.

No obstante, en la elaboración de obras particulares para ámbitos educativos en lengua materna, los países hispánicos pueden -y deben- concretar la descripción de las normas para su comunidad. Mantenerse en un nivel general es una aplicación ineficaz del principio del panhispanismo, considerado nocivo por especialistas como López García (2012), que se queja de su influencia en las escasas precisiones dialectales de libros escolares argentinos cuando "la norma consuetudinaria se confunde con la norma prescriptiva, e intentan 'explicar' los fenómenos lingüísticos desde una perspectiva descriptivista, ignorando los trabajos específicos sobre las variedades regionales” (129).

\section{EVIDENCIAS DEL LECTOCENTRISMO E IMPACTO DE PLURINORMATIVISMO EN LA ENSEŃANZA DEL E-L2/LE}

Tanto en la alfabetización de la lengua materna - aprender a leer y escribir- como en el aprendizaje de una nueva lengua, contamos con un modelo lingüístico reconocido por una comunidad lingüística nativa. Este modelo hace referencia "a una representación ejemplar o general de una lengua; se piensa en un modelo idealizado, construido como 
lengua ejemplar, elaborado a partir del uso o inducido desde él" (Moreno 2001: 5). Cuando esta comunidad es tan extensa como la del español, la diversidad cultural y lingüística es un desafío para su sistematización ya que "no es tarea fácil encontrar un arquetipo que sea a su vez modelo de corrección y prestigio y que se pueda considerar común o general" (Andión 2008: 12). Además, la enseñanza de la lengua recibe las creencias de las instituciones académicas y sujetos participantes (profesores y alumnos), que se ven reflejadas tanto en la docencia dentro del aula como en los materiales de estudio.

Antes de detenernos en los manuales de enseñanza-aprendizaje de E-L2/LE, mencionaremos el tratamiento de la variedad en dos importantes documentos de referencia para este ámbito, sobre todo en Europa, el Marco común europeo de referencia para las lenguas (MCER) y el Plan curricular del Instituto Cervantes (PCIC). Ambas obras, europea la primera y española la segunda, tienen en cuenta la diversidad (valores, creencias y actitudes relativos a aspectos socioculturales) como parte de la competencia. Por una parte, el MCER presta atención al "dialecto" y al "acento" en el apartado dedicado a la competencia sociolingüística (5.2.2.5): el aprendiz debe reconocer los marcadores lingüísticos (rasgos léxicos, fonológicos, prosódicos...) de la procedencia regional y el origen nacional de un nativo.

En el caso del español, lengua con varios referentes normativos, la elaboración del modelo lingüístico es una tarea compleja que requiere, al menos, considerar el estándar (común y neutro $\$ 2$ ) y una variedad preferente que responda a la situación concreta de aprendizaje y a las expectativas de los aprendices; además, deben tenerse en cuenta rasgos de variedades periféricas que muestren pluralidad lingüística (Andión 2007). Esta es la posición del $P C I C$, cuyos inventarios representan la norma culta de la variedad castellana (centro-norte peninsular española) y añaden otros rasgos hispánicos extensos (voseo, seseo, adverbialización de adjetivos, cierta morfología verbal...). Al respecto, Del Valle (2014) hace el siguiente comentario: "the Instituto's engagement in the teaching of Spanish is bound to a linguistic regime informed by ideologies of linguistic commodification, as well as by ideologies of standardization and pluricentricity" (364).

En los manuales de E-L2/LE, la tensión entre el modelo y sus variedades ha dejado huella. Es lógico pues sus creadores son hablantes de comunidades concretas, con sus creencias y actitudes. Al acercamos a ellos, resulta evidente una evolución en el tratamiento del modelo lingǘstico y la variedad del español. Diversos estudios sobre este tipo de materiales didácticos lo testimonian.

En las V Jornadas sobre Aspectos de la Enseñanza de E-L2/LE (Granada, España), Andión (1997) denunciaba que la competencia comunicativa no había sido entendida como propia del "español" en toda su extensión geográfica por un grupo de manuales españoles (1974-1995): Entre nosotros, Español en directo, Antena, Avance, Intercambio, Ven, Curso intensivo de español para extranjeros, Cumbre, Rápido y A fondo. Todos adscribían su modelo a la norma castellana, pero ninguno lo declaraba explícitamente. Aunque Andión (1997) explica esta preferencia por la filiación española de creadores y editoriales, es significativa la ausencia de alguna declaración sobre dicha adscripción en la introducción de los manuales (lugar esperable para este tipo de comentarios). Parece evidente que la creencia lectocentrista 
- tan extendida en esos años- justificaba no mencionar a qué zona lingüística correspondía la variedad preferente de las obras: la norma castellana era asumida como el paradigma de corrección de la lengua, parecía algo obvio.

Todos los manuales analizados, con excepción del Curso intensivo de español para extranjeros, mencionaban Hispanoamérica en sus contenidos culturales y lingüísticos. A este respecto, Andión (1997) anota, entre otros, la irregularidad de los rasgos atendidos, que evidenciaba la ausencia de un corpus preestablecido; los lapsus en la información (por ejemplo, tratar el voseo, pero olvidar mencionar sus desinencias verbales); la imprecisión de las áreas de uso; la ausencia de anotaciones sociolingüísticas pertinentes y de contrastes funcionales o de uso, como la cortesía. Volviendo a revisar hoy estos manuales, es lamentable la pobreza de contenidos allí donde la riqueza geolectal es más llamativa, la fonética.

Si avanzamos en el tiempo, encontramos un interesante estudio de García Fernández (2010). El autor analiza más de veinte manuales de E-L2/LE, publicados entre 1996 y 2007: varios españoles (Abanico, Aula Internacional, Eco, Es español, Español en marcha, Gente, Nuevo ELE, En acción, A fondo, Planet@, Primer plano, Procesos y recursos, Rápido, rápido, Socios, Así me gusta, Prisma), dos brasileños (Mucho, Vale), uno argentino (Voces del sur), uno destinado a México pero publicado en Espańa (Aula Latina) y dos dirigidos a brasileños pero también de editoriales españolas (Conexión, Mensajes). Solo el argentino declara que usa la norma rioplatense y explica por qué. Aula Latina se acoge a la mexicana-centroamericana pero no lo dice, aunque formula una queja abierta por la falta de correspondencia entre los materiales usados por los docentes mexicanos y su variedad. Mucho y Vale asumen la norma castellana, aunque se dirigen a brasileños e ignoran sistemáticamente los rasgos gramaticales americanos, actuación bastante difícil de justificar. El resto de los manuales sigue abiertamente el modelo centro-norte peninsular. A pesar de estas evidencias, "son apreciables los pequeños gestos que se empiezan a observar [...] los autores van incorporando cada vez más alusiones a las variedades del español de América”, aunque "en muchos de los manuales analizados estas referencias son inexactas o muy generales, lo que demuestra cierto desinterés por presentar con rigor aquellos rasgos que se desvían de la variedad preferente" (García Fernández, 2010, p. 99).

Recientemente, González Sánchez (2016) aplica un cuestionario de cuarenta preguntas sobre distintos aspectos a nueve manuales españoles de E-L2/LE (2004-2016) y en sus resultados se evidencia una evolución desde las posturas lectocentristas hacia el plurinormativismo. Las obras estudiadas son: Gente, El ventilador y Abanico (pertenecientes a la metodología conocida como "enfoque por tareas"), Nuevo Prisma, Bitácora y Aula Internacional (enseñanza orientada a la acción), Nuevo Avance, Dominio y Nuevo Ven (eclecticismo). Concretamente la pregunta 34 analiza ¿qué modelo de lengua se refleja en los materiales en cuanto a registros y variedades? En todos los casos la respuesta indica que la norma castellana es la variedad preferente. En mayor (Gente y muy destacadamente Bitácora) o en mucha menor medida (Abanico, Nuevo Avance, Nuevo Ven, Aula Internacional y Nuevo Prisma), los manuales tratan otros geolectos del español en contenidos y actividades, y trabajan las microdestrezas perceptivas para identificar rasgos prosódicos de la variación del 
español. La autora (2016) concluye que, entre los "muchos aspectos que todavía no son tratados en profundidad en los manuales y que, sin embargo, adquieren un papel importante en la formación del alumno y el desarrollo de sus competencias", está "la pronunciación, de las variedades dialectales" (116).

Flores y Andión (en prensa) hacen un estudio de seis manuales E-L2/LE, tres con la variedad del español peninsular como preferente (Bitácora, Nuevo español en marcha y Vente) y tres con otras variedades (Aula latina, dedicado al español de México; Latitud $0^{\circ}$, a un pupurrí de variedades; y Macanudo, al español argentino, más que rioplatense), todos publicados entre 2006 y 2014. Los rasgos observados por las autoras en su detallado análisis son algunos de los más extendidos y relevantes de la variación geolectal del español: el seseo, el yeísmo - con especial atención a su variante rehilada-, los pronombres personales vos-tú, ustedes-vosotros y sus repercusiones en las formas verbales, la diferencia de uso entre el pretérito perfecto compuesto y el pretérito perfecto simple, el futuro perifrástico ir a +infinitivo, la preposición hasta, rasgos léxicos varios, así como diferentes aspectos socioculturales. La principal conclusión del estudio es que, aunque aparecen aspectos relativos a las variedades del español en los manuales, su presencia es dispar y, en la mayoría de los casos, las referencias son escasas e imprecisas. Las autoras concluyen que los aspectos socioculturales de los países hispánicos (la gastronomía, el turismo, la economía, las lenguas que conviven con el espańol, las tradiciones, etc.) son los mejor representados.

En el panorama bibliográfico, son escasos los análisis de manuales hispanoamericanos. Quizás su producción es menor y más incipiente el interés de sus editoriales. Los trabajos consultados se centran en la presencia de Latinoamérica como referente geográfico y (socio) cultural, no en los aspectos lingüísticos. Pozzo (2014) estudia Pasaporte, Aula internacional (españoles), Voces del Sur y Por vos (argentinos), y denuncia el tratamiento exótico e icónico costumbrista de América Latina. En Eso sí, Mundos, Caminos, Vidas, Amigos, Tapas y Chicos, chicas, métodos suecos y noruegos usados también en Alemania y Holanda, Eide y Johnsen (2006) constatan que la visión de Hispanoamérica (y de España) es siempre exógena y europea, reflejada de "diferente manera y en diferente grado" (p. 9). ${ }^{12}$

Atender adecuadamente la diversidad lingüística en los manuales de enseñanza de E-L2/LE sigue siendo hoy una asignatura pendiente. El recorrido realizado -fundamentalmente por manuales españoles, pero no solo- evidencia testimonios suficientes de que las creencias lectocentristas son difíciles de desarraigar. También es justo reconocer que existe interés hacia otras variedades del español y sus rasgos idiosincrásicos. No obstante, la falta de rigor y sistematicidad con la que se aborda este tema hace pensar que no se ha alcanzado la madurez necesaria o que -y esto sería más lamentable- las editoriales no son conscientes de que necesitan reunir a equipos multidisciplinares que cuenten con especialistas en la materia.

\footnotetext{
${ }^{12}$ Existen otros trabajos interesantes sobre el análisis de la variación cultural y lingüística en los manuales de E-L2/LE, a saber, Baralo (2002), Castignani (2009), Hansejordet (2012), Prida (2014), entre otros. En ellos, se repiten algunas de estas ideas.
} 
Actualmente nadie debería dudar de que "entender la lengua como plurinormativa (además de plurisistemática) es fundamental para la enseñanza del idioma” (Camacho 2009: 336) y que:

Un buen presupuesto de partida es considerar que la lengua — nativa o de enseñanza- es un sistema vivo y vital, con el que sus hablantes dicen cosas distintas o las mismas valiéndose de recursos lingüísticos también variados, extraídos de inventarios extensos y en cuya selección actúan criterios de preferencia situacional, social y geográfica. Es decir, no todos los hablantes de una misma lengua hablamos igual, y esto es un derecho que encuentra sus límites cuando el interlocutor agota sus conocimientos activos y pasivos del código común y, por tanto, la comunicación fracasa (Andión 2008: 13).

Es más fácil que los manuales adopten esta postura si abordan la enseñanza del E-L2/LE desde un enfoque intercultural. Byram et al. (2002) reconocen su papel liberador:

The "intercultural dimensión" in language teaching aims to develop learners as intercultural speakers or mediators who are able to engage with complexity and multiple identities and to avoid the stereotyping which accompanies perceiving someone through a single identity. It is based on perceiving the interlocutor as an individual whose qualities are to be discovered, rather than as a representative of an externally ascribed identity (9).

Asumir la identidad plural del español convida a huir del lectocentrismo y abordar la variación del modelo de la lengua. Baralo (2002) propone asociar el concepto de mestizaje lingüístico al de interculturalidad e incluir en él:

el conocimiento de ciertas variedades diatópicas del español, de manera que un no nativo tenga la suficiente competencia como para procesar un mensaje que diferencie la /s/ y la $/ \Theta /$ y comprender ese mismo mensaje producido por un hablante seseante. De la misma manera que puede asimilar a su competencia en español una producción yeísta o con aspiración de la "s" o de la " $\mathrm{r}$ " en posiciones de coda silábica” (156).

Este es el marco idóneo para asumir un modelo lingüístico flexible para la enseñanza a no nativos que incluya necesariamente el estándar, pero que permita seleccionar la variedad preferente y considerar otras periféricas a esta. Ello facilitaría una adaptación adecuada a la naturaleza del curso (según a quién vaya dirigido y qué objetivos persiga), a las expectativas e intereses de los aprendices, al contexto (si es homosiglótico o heterosiglótico), entre otros aspectos a tener en cuenta. 
Debemos abordar la variación del español sin preconcebir que un rasgo es referente para el resto (es decir, sin convertir una variante en variable), sino que todas las realizaciones sean tratadas como variantes en sí mismas. Por ejemplo, para las grafías $z, c(+e, i)$ y $s$, existen en nuestra lengua tres variantes principales, de mayor a menor extensión:

Variante 1: El seseo, que consiste en realizar como/s/ las grafías $z, c(+e, i)$, por lo que en las zonas seseantes no existe $/ \theta /$ y pronuncian [s]apato zapato. Avala este rasgo su enorme extensión en el mundo hispánico: en España son seseantes los extremeños (del oeste y de puntos de sur), los andaluces (del centro y de puntos del oeste), los murcianos (del sur y el sureste) y los canarios; y también lo son en toda Hispanoamérica. Atendiendo a varias circunstancias (lugar y situación de enseñanza, referencias hispánicas, intereses de los aprendices, etc.), el profesor debe decidir si el seseo formará parte del modelo preferente de sus alumnos o deberá tener un lugar dentro del programa como rasgo periférico. Un ejemplo de localización curricular, puede ser el nivel inicial bajo (A1, según el $M C E R$ ) o a partir de este al atender los fonemas y sus variantes en la identificación y producción de los fonemas consonánticos.

Variante 2: La distinción entre la fricativa (inter)dental sorda / $\theta /$ para las grafías $z$, $c(+e, i)$ y la fricativa alveolar sorda /s/ para la $s$, de lo que resulta la pronunciación diferenciada de ca[$[\theta]$ a caza y ca[s]a casa. Este rasgo, tan favorecido por el lectocentrismo, en realidad es exclusivo de una parte de España: hablantes castellanos, extremeños y murcianos de algunas zonas, andaluces (del norte, sobre todo del este), a los que se añaden los de algunas pequeñas zonas hispanoamericanas (costas caribeńas de Colombia, por ejemplo). Si se opta por un modelo distinguidor, este será parte de la variedad preferente. Pero si asumimos un modelo seseante, la distinción puede mencionarse como periférica en el nivel inicial alto (A2, según el $M C E R)$ o a partir de este, cuando se traten los fonemas y sus variantes.

Variante 3: El ceceo, fenómeno en el que la letra $s$ se realiza como fricativa (inter) dental sorda $/ \theta /$, por lo que en las zonas ceceantes no existe $/ \mathrm{s} /$ y se dice $[\theta]$ aber saber. Es propio del sur centro-oeste de Andalucía (España) y de pequeños islotes zonales hispanoamericanos (en Centroamérica: Costa Rica, El Salvador, Guatemala, zona norte de Nicaragua, Honduras; en el Caribe: varios puntos costeros de Colombia, Panamá, Puerto Rico, República Dominicana (en nivel sociocultural bajo), costas de Venezuela (en nivel sociocultural bajo); en los Andes: varios puntos andinos de Colombia, Bolivia; y en el Río de la Plata: algunas provincias de Argentina y parte oriental de Paraguay) (Andión y Casado, 2014). Tal y como hemos recomendado, con un modelo preferente seseante o distinguidor, el ceceo puede tratarse en el nivel superior $(\mathrm{C} 1$ o $\mathrm{C} 2$, según el $M C E R)$, al hablar de los fonemas y sus variantes.

Este paralelismo de variantes es coherente con el reconocimiento de la identidad plural del español, lo que permite huir del lectocentrismo y abordar con equidad la variación desde el plutinormativismo, independientemente de la orientación del modelo preferente que se seleccione. 


\section{Conclusiones}

La lengua, como parte de la cultura, puede ser víctima del etnocentrismo, más concretamente del glotocentrismo. Cuando esta actitud de carácter psicológico afecta, en exclusiva, a los geolectos de una lengua, merece una denominación propia, a la que hemos propuesto llamar lectocentrismo.

La larga historia del mundo hispánico y la multitud de pueblos europeos y americanos participantes en ella han sido testigos de no pocos episodios etnocentristas, propiciados por el pasado colonial y esclavista de sus sociedades multiétnicas. Consecuentemente, sus variedades han padecido actitudes lectocentristas favorecedoras de la variedad castellana (centro-norte peninsular) en Espańa y, además, de la colombiana en Hispanoamérica. No obstante, desde finales del siglo XX se produce una moderación del privilegio geolectal castellano y se revalúa su representatividad desde una postura plurinormativa. Varios factores han propiciado esta evolución: la democratización de España, el boom de la literatura hispanoamericana, el auge de las relaciones con Hispanoamérica y la política de ASALE, entre otros. Todos ellos han ayudado a que las autoridades lingüísticas del mundo hispánico apuesten hoy por el panhispanismo y el plurinormativismo, de los que dan fe sus obras conjuntas.

Estos avatares glotopolíticos se reflejan en la enseñanza-aprendizaje de E-L2/LE y la presencia de los geolectos se abre camino con paso más o menos seguro. Tras repasar el análisis de más de sesenta manuales, muchos muestran un modelo lectocentrista y/o presentan otras variedades $-\mathrm{y}$ sus comunidades- de manera folclórica y exótica. Aunque resulta legítimo que este tipo de obra escoja una variedad preferente como modelo, decisión sobre la que se pueden esgrimir argumentos razonados y convenientes, no lo es que esta se presente como referente único de la lengua y que sus rasgos exclusivos se muestren como generales. Mucho menos lo sería ignorar la variación concomitante, sobre todo la que está apoyada en razones de pertinencia, demografía y extensión.

Reconocemos que hoy los manuales de E-L2/LE reflejan la variación con más frecuencia, acierto y rigor. Los dialectólogos empiezan a aparecer entre sus créditos editoriales. Es lógico y un motivo de alivio. A estas alturas del desarrollo de la Lingüística aplicada a la enseñanza del español y existiendo una bibliografía especializada (Andión 2007; Andión 2008; Andión y Casado 2014; Baralo 2002; Moreno 2010, 2014), el desconocimiento y la inconsciencia no justifican posturas lectocentristas en creadores, editoriales, diseñadores curriculares o autoridades académicas; mucho menos en docentes, aunque no sean intencionadas. Debemos alertar sobre ellas y cohesionar el tratamiento de la variación/variedad en E-L2/LE con el marco glotopolítico actual, en coherencia con la realidad plurinormativa del español y, lo que es más importante, para beneficio de nuestros aprendices; también, por qué no, por justicia con los pueblos hispanohablantes. 


\section{Obras CITADas}

Aguilera, R. 2008. El problema del etnocentrismo en el debate antropológico entre Clifford Geertz, Richard Rorty y Lévi-Strauss. Gazeta de Antropología 18, 11. Web.

Alba, O. 2004. Cómo hablamos los dominicanos. Un enfoque sociolingüistico. Santo Domingo: Grupo León Jimenes.

Alvar, M. 1996. ¿Qué es un dialecto? En M. Alvar, ed., Manual de dialectología hispánica. El español de España. Barcelona: Ariel. 5-14

Andión, M. ${ }^{a}$ A. 1997. Los Manuales de Enseñanza de Español como lengua extranjera y el español de América. Consideraciones. En A. Martínez González et al., eds., Enseñanza de Lenguas Extranjeras. Actas de las V Jornadas sobre Aspectos de la Enseñanza del Español como Lengua Extranjera. Granada, España: Universidad de Granada, Grupo de Lingüística Aplicada. 27-36

Andión, M. ${ }^{a}$ A. 2007. Las variedades y su complejidad conceptual en el diseño de un modelo lingüístico para el español L2/LE. Estudios de Lingüistica ELUA 21: 21-33.

Andión, M. a A. 2008. Modelo, estándar y norma...Conceptos aplicados en el español L2/ LE. Revista Española de Lingüistica Aplicada RESLA 21: 9-25.

Andión, M. ${ }^{a}$ A. 2013. Los profesores de español segunda/lengua extranjera y las variedades: Identidad dialectal, actitudes y prácticas docentes. Revista Signos. Estudios de Lingüistica 46, 82: 155-189.

Andión, M. ${ }^{a}$ A. y Casado, C. 2014. Variación y variedad del español aplicadas a E-LE/L ${ }_{2}$. Madrid: Editorial UNED.

Arnoux, E. N. de 2015. El español global y la regulación de la discursividad en línea como piezas del dispositivo glotopolítico panhispánico. En P. Roca y S. Tavares, eds., Politicas linguisticas declaradas, praticadas e percebidas. João Pessoa: UFPB. 35-68.

Baralo, M. 2002. Mestizaje e interculturalidad en la variación diatópica y su incidencia en español/LE. En M. Pérez y J. Coloma, eds. Actas del XIII Congreso de ASELE. Murcia: Universidad de Murcia. 152-164.

Bello, A. 1853 [1847]. Gramática de la lengua castellana. Madrid: Imprenta de la biblioteca económica de educación y enseñanza.

Bravo, E. 2008. El español internacional. Conceptos, contextos y aplicaciones. Madrid: Arco/ Libros.

Byram, M., Gribkova, B., y Starkey, H. 2002. Developing the intercultural dimension in language teaching. A practical introduction for teachers. Strasbourg, France: Council of Europe.

Camacho, L. 2009. El español coloquial en contexto académico. En A. Vera e I. Martínez Eds., XX Congreso Internacional de la ASELE. Comillas, España: Fundación Comillas. 331-346.

Castagnani, T. 2009. La representación de Hispanoamérica en dos manuales de ELE de nivel avanzado. Trabajo Final de Máster. Barcelona: Universitat de Barcelona-Universitat Pompeu Fabra. 
Chiriguini, M.a , y Mancusi, M. 2008. El etnocentrismo: una clase particular de sociocentrismo. En M. Chiriguini, comp., Apertura a la Antropología: alteridad, cultura, naturaleza humana. Buenos Aires, Argentina: Proyecto editorial. 79-92.

Consejo de Europa 2002. Marco común europeo de referencia para las lenguas. Madrid: MECD-Anaya.

Coseriu, E. 1981. Lecciones de lingüistica general. Madrid: Gredos.

Cros, E. 2009. La sociocritica. Madrid: Arco/Libros.

De Andrés, R. 1997. Lingüística y sociolingüística en el concepto del dialecto I y II. Contextos 29-30: 67-108.

Demonte, V. 2003. Lengua estándar, norma y normas en la difusión actual de la lengua española. Circunstancia 1: 1-23.

Edwards, J. 1994. Languages and identities. En J. Edwards, Multilingualism. London: Routledge. 125-145

Eide, L., y Johnsen, A. 2006. La presencia de América Latina en los métodos de E/LE en Noruega. En J. Izquierdo et al., I Congreso Nacional de la Asociación Noruega de Profesores de Español. 1-10.

Ember, C. y Ember, M. 1997. Antropología Cultural. Madrid: Prentice May.

Flores, S. y Andión, M. ${ }^{a}$ A. en prensa. Qué español enseñamos: El tratamiento de las variedades en manuales de ELE/L2. Revista de lingüistica y lenguas aplicadas.

García de Diego, V. 1950. El castellano como complejo dialectal y sus dialectos internos. Revista de Filologia Española XXXIV: 107-124.

García Fernández, E. 2010. El tratamiento de las variedades de español en los manuales de EL2/LE. Trabajo del Diploma de Estudios Avanzados. Madrid: UNED.

González Aróstegui, M. del R. 2003. Fernando Ortiz y la polémica del panhispanismo y el panamericanismo en los albores del siglo XX en Cuba. Revista de Hispanismo Filosófico 8: 5-18.

González Cruz, M. ${ }^{a}$ I. 1995. Lengua, prestigio y prejuicios lingüísticos: Algunas consideraciones sobre el español. Revue belge de philologie et d'histoire 733: 715-723.

González Sánchez, M. ${ }^{a}$ 2016. Análisis metodológico de manuales de español para extranjeros: últimas aportaciones y perspectivas de futuro. Trabajo Fin de Máster. Madrid: UNED.

Hansejordet, I. 2012. La marginación de la literatura y de Hispanoamérica en el español como lengua extranjera. Nordic Journal of Modern Language Methodology 11: 1-15.

Instituto Cervantes 2006. Plan Curricular del Instituto Cervantes. Madrid: Editorial Biblioteca Nueva, S. L.

Instituto Cervantes 2016. El español: una lengua viva. Informe 2016. Madrid: Instituto Cervantes.

Lander, E., comp. 2005. La colonialidad del saber: eurocentrismo y ciencias sociales. Perspectivas latinoamericanas. Buenos Aires: CLACSO.

Lévi-Strauss, C. 1974. Presentación y antología de textos. Barcelona: Anagrama.

Lipski, J. 1996. El español de América. Madrid: Cátedra.

López García, M. 2012. La enseñanza de la lengua escolar como proyecto de identidad 
nacional: el contexto socio educativo. Revista argentina de historiografía lingüistica IV2: 117-132.

Lozano, M. 1999. El Departamento de Dialectología del Instituto Caro y Cuervo. Cincuenta años de labores 1949-1999. Presentación. THESAURUS LIV2: 529-533.

Moreno Fernández, F. 2001. Prototipos y modelos de lengua. Carabela. Modelos de uso de la lengua española 50: 5-20.

Moreno Fernández, F. 2006. "Los modelos de lengua. Del castellano al panhispanismo". En A. Cestero ed., Lingüistica aplicada a la enseñanza de español como lengua extranjera: desarrollos recientes. Madrid: Universidad de Alcalá. 75-94

Moreno Fernández, F. 2007. Qué español enseñar. Madrid: Arco/Libros.

Moreno Fernández, F. 2010. Las variedades de la lengua española y su enseñanza. Madrid: Arco/Libros.

Moreno Fernández, F. 2014. La lengua española en su geografía. Manual de dialectología hispánica. Madrid: Arco/Libros.

Morgenthaler, L. 2008. Identidad y pluricentrismo lingüistico. Hablantes canarios frente a la estandarización. Frankfurt-Madrid: Vervuert Iberoamericana.

Patiño, C. 2004. Aspectos del lenguaje en Colombia. Cuadernos del CES 4: 3-13.

Pozzo, M. ${ }^{a}$ 2014. Contenidos socioculturales sobre América Latina en manuales de español lengua extranjera de España y Argentina. Sures 3: 1-15.

Prida, C. 2014. La cultura hispanoamericana en las clases de ELE: Nuevas perspectivas y aplicaciones. Trabajo Final de Máster. Oviedo: Universidad de Oviedo.

Rabanales, A. 1998. Unidad y diversificación de la lengua. ONOMAZEIN 3: 133-142.

Real Academia Española y Asociación de Academias de la Lengua Española 1999. Ortografía de la lengua española. Madrid: Espasa.

Real Academia Española. 2001. Diccionario de la lengua española. Madrid: Espasa.

Real Academia Española y Asociación de Academias de la Lengua Española. 2005. Diccionario panhispánico de Dudas. Madrid: Santillana.

Real Academia Española y Asociación de Academias de la Lengua Española. 2014. Diccionario de la lengua española. Madrid: Espasa.

Real Academia Española y Asociación de Academias de la Lengua Española. 2009-2011. Nueva gramática de la lengua española. Madrid: Espasa.

Richards, J. C., Platt, J. y Platt, H. 1997. Diccionario de lingüistica aplicada y enseñanza de lenguas. Barcelona, España: Ariel.

Rodríguez Marcos, J. 2011. “En ningún sitio se habla el mejor español del mundo”. El País. Web.

Stewart, W. 1974 [1962]. Un bosquejo de tipología lingüística para describir el multilingüismo. En P. L. Garvin y Y. Lastra, Antología de estudios de etnolingüistica y sociolingüistica. México: UNAM. 224-233

Sumner, W. 1959 [1906]. Folkways: A Study of the Sociological Importance of Usages, Manners, Customs, Mores, and Morals. Nueva York: Dover.

Valle, J. del 2007. La lengua, patria común: la hispanofonía y el nacionalismo panhispá- 
nico. En J. del Valle coord., La lengua, ¿patria común? Madrid-Frankfurt, España: Vervuert Iberoamericana. 31-46

Valle, J. del 2014. The Politics of Normativity and Globalization: Which Spanish in the Classroom? The Modern Language Journal 98: 358-372.

Vergara, J. 2007. La norma policéntrica del español: Una visión desde la teoría de la complejidad y el caos. IV Congreso Internacional de la Lengua Española.Madrid: Instituto Cervantes.

Walsh, C. ed. 2005. Pensamiento crítico y matriz de colonial. Quito: Universidad Andina Simón Bolívar. 